TITLE:

\title{
Preparation of nanosized metal (oxides) by gas phase hydrolysis using mesoporous materials as nanoreactors
}

\section{$\operatorname{AUTHOR}(S):$}

Ingmar, Gerlach; Kawase, Motoaki; Miura, Kouichi

\section{CITATION:}

Ingmar, Gerlach ... [et al]. Preparation of nanosized metal (oxides) by gas phase hydrolysis using mesoporous materials as nanoreactors. Journal of Nanoparticle Research 2009,

11(8): 2049-2059

ISSUE DATE:

2009-11

URL:

http://hdl.handle.net/2433/87732

\section{RIGHT:}

c 2008 Springer Science+Business Media B.V.; This is not the published version. Please cite only the published version.; この論文は出版社版で ありません。引用の際には出版社版をご確認ご利用ください。 


\section{Preparation of Nanosized Metal Oxides by Gas Phase}

\section{Hydrolysis Using Mesoporous Materials as}

\section{Nanoreactors}

Ingmar Gerlach, Motoaki Kawase, Kouichi Miura

Department of Chemical Engineering, Kyoto University, Kyoto 615-8510 Japan

kawase@cheme.kyoto-u.ac.jp

* To whom correspondence should be addressed. E-mail: kawase@cheme.kyoto-u.ac.jp, Tel.: +81-75383-2683, Fax: +81-75-383-2653

ABSTRACT: Nanosized metal (oxides), which were immobilized on carbonaceous carriers, were prepared by hydrolysis at very mild conditions by using the pores of the carrier material as a kind of nanoreactor. Metal alkoxide precursors were first adsorbed on the carrier material from the vapor phase and then exposed to water vapor to undergo hydrolysis reaction and form the product. With this facile method, titania, vanadia, rhodium (oxide) and platinum (oxide) nanostructures were prepared at high yields and high loadings on the carrier material. Metal (oxide) was well-dispersed in the carrier material. Extremely high number concentrations of spheroidal nanoparticles with a uniform size-distribution (ca. $5 \mathrm{~nm}$ in diameter) were obtained in case of using precursors with a low reactivity, whereas no such particles were formed from highly reactive precursors. However, with a subsequent calcination, such nanoparticles could be obtained even in the samples prepared from highly reactive precursors. This suggested that nanosized particles may be the thermodynamically stable form of the metal (oxide) 
produced in the pores. With highly reactive precursors, supposedly metastable seeds for nanoparticles were formed. Upon subsequent exposure to heat, these could nucleate and restructure into nanosized, spheroidal particles. The hydrolysis of metal alkoxides within the pores of mesoporous materials and subsequent calcination thus gave the means to prepare nanosized metal (oxide) structures and to effectively control their size and shape.

KEYWORDS: Nanoreactor, Metal nanoparticles, Metal oxide nanoparticles, Alkoxide, Hydrolysis

\section{Introduction}

Nanosized materials, in particular nanoparticles, are of tremendous scientific interest, ${ }^{1,2}$ also with respect to catalytic applications. The unique chemical and physical properties of nanomaterials allow for drastic improvement of the catalyst efficiency. ${ }^{3}$ To provide nanomaterials in utilizable form, a common approach is to stabilize them against agglomeration and sintering by immobilization on a carrier material. ${ }^{3,4}$ We recently proposed a method utilizing the pores of carrier materials as a nanoreactor for the pyrolysis of titanium alkoxide to prepare immobilized, nanosized titania on carbon carriers. ${ }^{5}$ With this unique nanoreactor concept, immobilized titania was obtained at high yields and exclusively inside the carrier pores. However, not all of the titania appeared to have particulate form. It is therefore interesting to understand the mechanism and influencing parameters of particle formation.

In this study we implemented the nanoreactor concept also for hydrolysis reactions of metal alkoxide precursors to prepare a variety of supported metal (oxide) nanostructures. The concept of gas phase hydrolysis in nanoreactors is illustrated in Figure 1. Depending on their reactivities, bulk phase metal alkoxide precursors (solid or liquid) can react if exposed to water (vapor), however only at the interface and only until they are covered by a deposit of product, which quenches the reaction. If adsorbed on a macroscale surface (usually in a multilayer), contact probability of the reactant molecules is drastically enhanced leading to higher conversion. However, if the adsorbed sample is brought into an environment without the precursor molecule being present in the gas phase, most of the precursor will merely desorb before reacting, so that the product yield will still be low. On the other hand, if the precursor is adsorbed 
in the nanosized pores of a mesoporous carrier material, its desorption is retarded due to the effect of capillary condensation. Furthermore, desorbed reactant molecules need time to diffuse out of the carrier pores and are likely to be subject to reaction before reaching the pore mouths. Gaseous byproducts can be easily removed through the pore apertures.

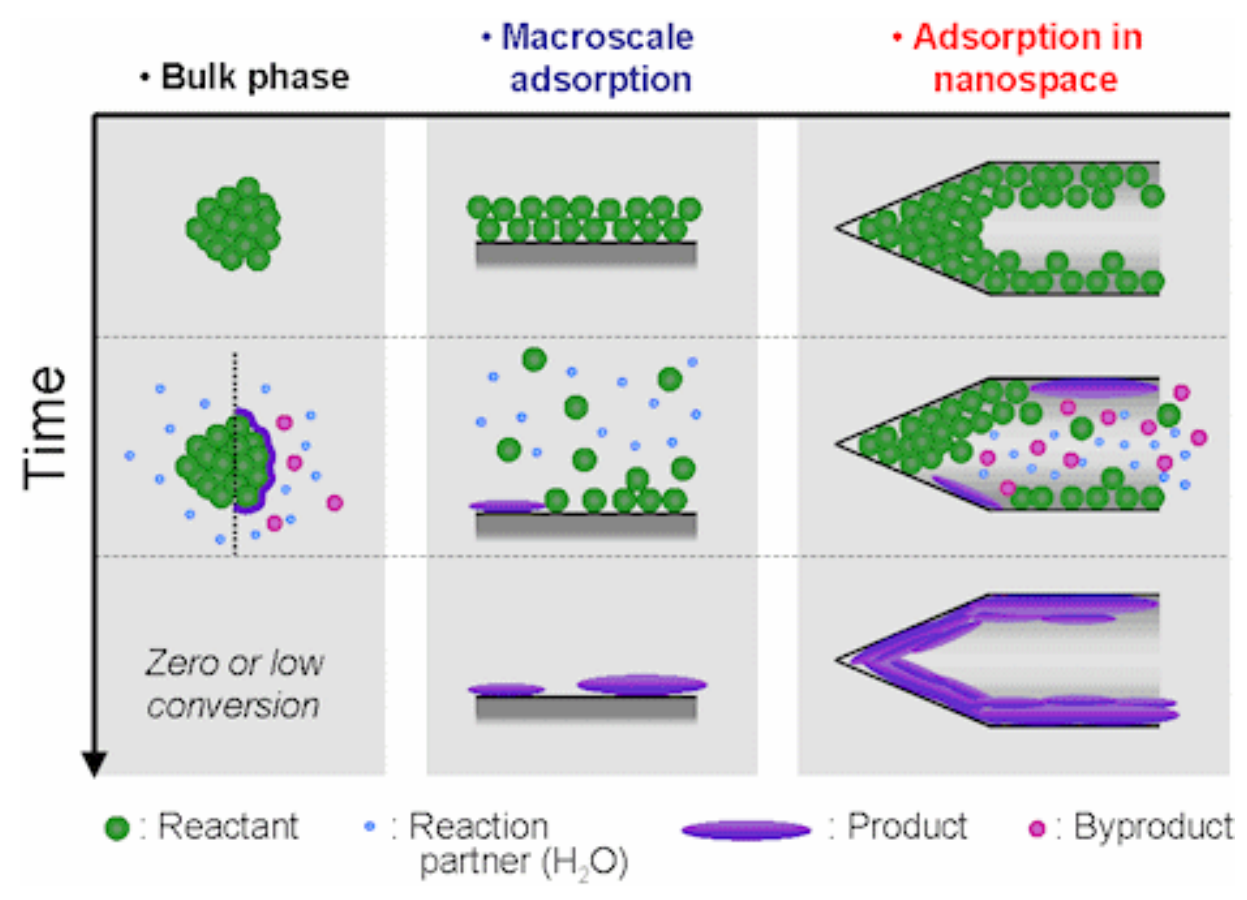

Figure 1. Concept of gas phase hydrolysis in nanoreactors

Since the gas phase hydrolysis can be conducted under relatively mild conditions, the chemical reaction to form the product could be carried out without exposure to heat. Heat was subsequently applied by annealing of the product material. This approach allowed for decoupling of chemical reaction and exposure to heat and studying the effects of precursor reactivity and elevated temperatures on the tendency to form spheroidal nanosized particulates separately.

Metal alkoxide precursors were at first adsorbed on the carrier material. To form the product, hydrolysis was then carried out by exposing the adsorbed precursor to water vapor. Product materials were characterized in terms of shape and loading of metal (oxide) on the carrier material. The change in the pore structure of the carrier material by the product formation in the pores was investigated exemplary for titania produced in an ordered pore structure. 


\section{Experimental}

Materials. For carrier materials, a commercially available activated carbon (AC) (Diahope 006, Mitsubishi Chemical Corp.) with a random pore structure and an ordered mesoporous carbon (OMC) were employed. The latter was prepared from furfuryl alcohol as described in the literature ${ }^{6}$ with the aid of a self-synthesized SBA-16 silica template. ${ }^{7}$

The nitrogen adsorption isotherm at $77 \mathrm{~K}$ was measured for the pure carrier materials with the aid of a Belsorp 28 volumetric adsorption apparatus (Bel Japan, Inc.) and BET surface area and mesopore size distribution were calculated, the latter by means of the Dollimore-Heal method. ${ }^{8,9}$ The ash contents of the carrier materials were determined by thermogravimetric (TG) analysis (Perkin Elmer Pyris 1 TGA) under a flow of He containing $22 \% \mathrm{O}_{2}$.

The precursors for metal (oxide) formation were metal alkoxides purchased from Kishida Chemicals and Sigma-Aldrich. Molecules and basic properties of each precursor are shown in Figure 2.

\begin{tabular}{|c|c|c|c|c|}
\hline $\begin{array}{l}\text { Titanium(IV) } \\
\text { tetramethoxide } \\
\text { (TTM) }\end{array}$ & $\begin{array}{l}\text { Titanium(IV) } \\
\text { tetraisopropoxide } \\
\text { (TTIP) }\end{array}$ & $\begin{array}{l}\text { Vanadium(V) } \\
\text { oxytriisopropoxide } \\
\text { (VOTIP) }\end{array}$ & $\begin{array}{l}\text { Rhodium(I) dicarbonyl } \\
\text { acetylacetonate } \\
\text { (RhDCAA) }\end{array}$ & $\begin{array}{l}\text { Platinum(II) } \\
\text { acetylacetonate } \\
\text { (PtAA) }\end{array}$ \\
\hline 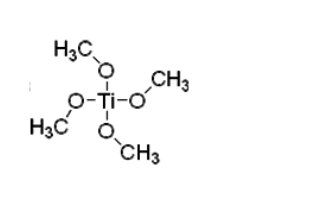 & & $\begin{array}{c}\mathrm{CH}_{3} \mathrm{O} \mathrm{CH}_{3} \\
\mathrm{CH}_{3} \mathrm{CHO}-\mathrm{V}-\mathrm{O}-\mathrm{OCHCH}_{3} \\
\mathrm{O} \mathrm{OCHCH}_{3} \\
\mathrm{OCHCH}_{3} \\
\mathrm{CH}_{3}\end{array}$ & 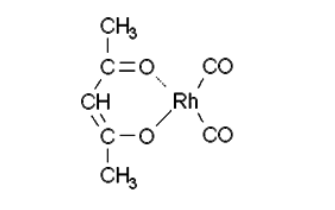 & {$\left[\begin{array}{c}\mathrm{CH}_{3} \\
\mathrm{I}=\mathrm{O} \\
\mathrm{C}=\mathrm{O} \\
\mathrm{CH} \\
\mathrm{C}^{\mathrm{C}}-\mathrm{O} \\
\mathrm{C} \\
\mathrm{CH}_{3}\end{array}\right]_{2}$} \\
\hline $\begin{array}{l}\text { solid }\left(T_{\text {melt }}=200-210^{\circ} \mathrm{C}\right) \\
M_{\mathrm{r}}=172 \mathrm{~g} / \mathrm{mol} \\
d_{\text {molec. }} \approx 0.8 \mathrm{~nm}\end{array}$ & $\begin{array}{l}\text { liquid }\left(T_{\text {melt }}=14-17^{\circ} \mathrm{C}\right) \\
M_{\mathrm{r}}=284.2 \mathrm{~g} / \mathrm{mol} \\
d_{\text {molec. }} \approx 1.1 \mathrm{~nm}\end{array}$ & $\begin{array}{l}\text { liquid }\left(T_{\text {boil }}=80-82^{\circ} \mathrm{C}\right) \\
M_{\mathrm{r}}=244.2 \mathrm{~g} / \mathrm{mol} \\
d_{\text {molec }} \approx 0.9 \mathrm{~nm}\end{array}$ & $\begin{array}{l}\text { solid }\left(T_{\text {melt }}=154-156^{\circ} \mathrm{C}\right) \\
M_{\mathrm{r}}=258.03 \mathrm{~g} / \mathrm{mol} \\
d_{\text {molec. }} \approx 1.0 \mathrm{~nm}\end{array}$ & $\begin{array}{l}\text { solid }\left(T_{\text {melt }}=? ? ?\right) \\
M_{\mathrm{r}}=393.29 \mathrm{~g} / \mathrm{mol} \\
d_{\text {molec }} \approx 1.3 \mathrm{~nm}\end{array}$ \\
\hline
\end{tabular}

Figure 2. Precursors for nanosized metals and metal oxides

The largest molecule, PtAA, had a diameter of about $1.3 \mathrm{~nm}$, therefore all reactants were considered to be able to intrude even into the small mesopores of the carrier materials. Theoretical stoichiometries of the hydrolysis reactions of the alkoxides can be formulated as follows:

TTM: $\quad \mathrm{Ti}\left[\mathrm{OCH}\left(\mathrm{CH}_{3}\right)_{2}\right]_{4}+2 \mathrm{H}_{2} \mathrm{O} \rightarrow \mathrm{TiO}_{2}+4\left(\mathrm{CH}_{3}\right)_{2} \mathrm{CHOH}$ 


$$
\text { TTIP: } \quad \mathrm{Ti}\left(\mathrm{OCH}_{3}\right)_{4}+2 \mathrm{H}_{2} \mathrm{O} \rightarrow \mathrm{TiO}_{2}+4 \mathrm{CH}_{3} \mathrm{OH}
$$

VOTIP: $\quad \mathrm{OV}\left[\mathrm{OCH}\left(\mathrm{CH}_{3}\right)_{2}\right]_{3}+3 / 2 \mathrm{H}_{2} \mathrm{O} \rightarrow 1 / 2 \mathrm{~V}_{2} \mathrm{O}_{5}+3\left(\mathrm{CH}_{3}\right)_{2} \mathrm{CHOH}$

$$
\text { RhDCAA: } \quad \mathrm{Rh}(\mathrm{CO})_{2}\left(\mathrm{C}_{5} \mathrm{H}_{7} \mathrm{O}_{2}\right)+\mathrm{H}_{2} \mathrm{O} \rightarrow \mathrm{RhOH}+\left(\mathrm{C}_{5} \mathrm{H}_{7} \mathrm{O}\right) \mathrm{OH}+2 \mathrm{CO}
$$

$$
\text { PtAA: } \quad \operatorname{Pt}\left(\mathrm{C}_{5} \mathrm{H}_{7} \mathrm{O}_{2}\right)_{2}+2 \mathrm{H}_{2} \mathrm{O} \rightarrow \mathrm{PtO}+\left(\mathrm{C}_{5} \mathrm{H}_{7} \mathrm{O}\right) \mathrm{OH}
$$

These are theoretical equations and it was assumed that $\mathrm{Rh}_{2} \mathrm{O}_{3}$ was formed rather then $\mathrm{RhOH}$ and in case of PtAA, the $\mathrm{Pt}(0)$ metal may possibly have formed instead of its oxide.

Precursor adsorption. After grinding (grain size $\leq 150 \mu \mathrm{m}$ ) and heat-treating $\left(30 \mathrm{~min}\right.$ at $1200{ }^{\circ} \mathrm{C}$ under $\mathrm{N}_{2}$ flow), ca. $0.5 \mathrm{~g}$ of the carrier material were contacted with the precursor vapor in the adsorption apparatus shown in Figure 3. A glove box filled with nitrogen was used for these preparations, since TTIP and VOTIP are sensitive to humidity. The adsorption was carried out in a vacuum of $1 \mathrm{kPa}$ and at a temperature between 70 and $100{ }^{\circ} \mathrm{C}$. The adsorption period was several days in order to attain equilibrium adsorption of the precursor on the carrier. Henceforth, the carrier material loaded with the precursor compound will be designated as "parent material" in general, or the respective combination will be denoted in the order precursor/carrier (e.g. TTM/OMC). Alkoxide will be abbreviated to "Alk.”.

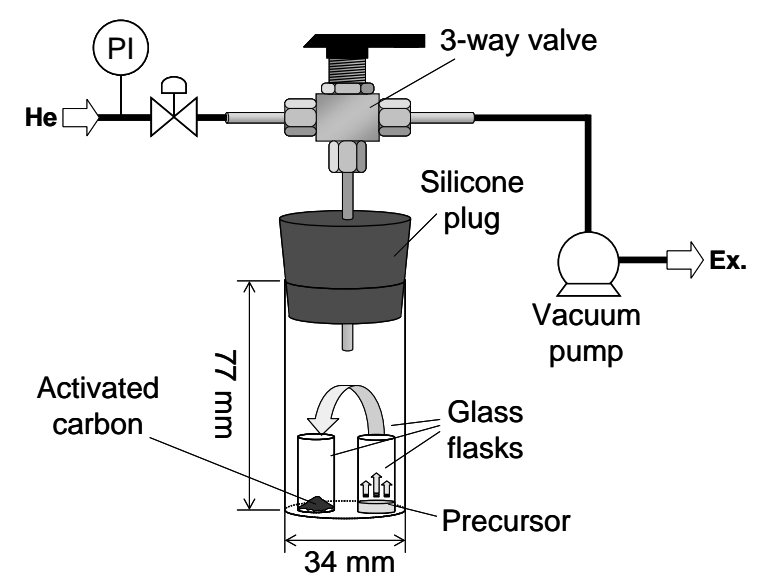

Figure 3. Apparatus for adsorption of precursor vapors on the carrier materials 
Hydrolysis. Formation of metals and metal oxides was achieved by exposure of each parent material to water vapor using the same apparatus as for the precursor adsorption. A small glass flask was filled with a sample of parent material and was placed together with another small flask filled with water in the larger flask, which was then capped with a silicone plug. After repeating evacuation and flushing with helium, the flask was finally evacuated with a pumping pressure of $1 \mathrm{kPa}$ and was then placed in an oven at $70{ }^{\circ} \mathrm{C}$, which complies with a water vapor pressure of approximately $31 \mathrm{kPa}$. A moderate temperature was chosen for a low desorption rate of the precursor from the carrier. Evacuation was to obtain an atmosphere consisting mainly of saturated water vapor and to facilitate diffusion of the water molecules to the reactant adsorbed in the small carrier pores.

Calcination. After $1-2$ days of reaction, product samples were dried in a vacuum oven at $110{ }^{\circ} \mathrm{C}$. A subsequent heat-treatment was carried out for $2 \mathrm{~h}$ at $800^{\circ} \mathrm{C}$ under a flow of nitrogen gas.

Henceforth, metal (oxide) will be abbreviated to "M(Ox.)". The carrier material loaded with the obtained metal (oxide) compound will be designated as "hydrolysis product", and as "calcined product" after the heat treatment, in general. A particular sample will be denoted by the respective combination in the order metal (oxide)/carrier (e.g. $\mathrm{TiO}_{2} / \mathrm{OMC}$ ). The annex “-HT” will indicate a specific sample after calcination, e.g. $\mathrm{TiO}_{2} / \mathrm{OMC}-\mathrm{HT}$.

Product characterization. Product materials were analyzed by a scanning electron microscope (SEM) (JEOL JSM-6340 FS), equipped with an energy dispersive spectrometer (EDS) (Oxford Instruments 7158) for analysis of the elemental composition. Chemical structure of the product was examined by X-ray photoelectron spectroscopy (XPS) (Shimadzu ESCA 750). Product shape was observed by transmission electron microscopy (TEM) (JEOL JEM-1010) at an acceleration voltage of $100 \mathrm{kV}$. Crystallinity of all samples was investigated by X-ray diffractometer (Shimadzu XD-610) using $\mathrm{Cu} \mathrm{K} \alpha$ radiation. Precursor loadings on the parent materials and product metal (oxide) contents of the 
product materials were determined by combustion of the carbon material in a thermogravimetric (TG) analyzer (Perkin Elmer Pyris 1TGA) under a flow of nitrogen containing 22 \% oxygen. The calculation method was explained in a previous publication. ${ }^{6}$ Nitrogen adsorption isotherms and derived mesopore size distributions of product samples were compared to those of the pristine carrier materials.

\section{Results and discussion}

Precursor and product loadings. Loadings of the metal alkoxides on the carbon carriers on both molar and mass bases are listed in Table 1. Precursor loadings differed vastly between 0.04 g (g-carrier) ${ }^{1}$ for PtAA and as high as $1.36 \mathrm{~g}$ (g-carrier) ${ }^{-1}$ in case of TTIP. This was due to the different vapor pressures and molecular sizes of each precursor.

Table 1. Alkoxide loadings on AC and OMC carriers

\begin{tabular}{ccccccc}
\hline & TTIP/OMC & TTIP/AC & TTM/AC & VOTIP/AC & RhDCAA/AC & PtAA/AC \\
\hline $\begin{array}{c}\text { molar loading / } \\
\text { mol (g-carrier) }\end{array}$ & $9.2 \times 10^{-4}$ & $4.8 \times 10^{-3}$ & $5.8 \times 10^{-4}$ & $1.7 \times 10^{-3}$ & $3.4 \times 10^{-4}$ & $1.2 \times 10^{-4}$ \\
$\begin{array}{c}\text { weight loading / } \\
\text { g (g-carrier) }\end{array}$ & 0.26 & 1.36 & 0.10 & 0.43 & 0.09 & 0.04 \\
\hline
\end{tabular}

Weight loss curves for the combustion of hydrolysis products are shown in Figure 4. No alkoxide desorption could be detected in the weight loss curves of product samples, thus hydrolysis reaction was completed. Metal (oxide) loadings and yields determined from the sample weights after combustion of the carbon carrier are listed in Table 2. In case of the rhodium precursor, a mixture of rhodium and its oxides with different oxidation numbers were formed (see following section). Therefore the oxidation number +III was arbitrarily presumed in Table 2 . 


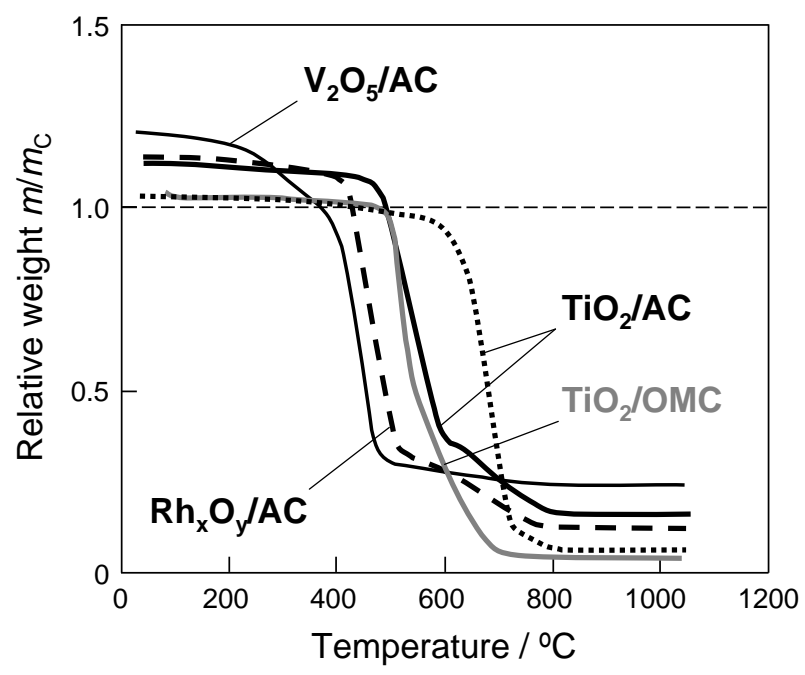

Figure 4. Weight loss curves for combustion of product materials $\mathrm{M}(\mathrm{Ox}.) / \mathrm{AC}$ (black lines) and $\mathrm{TiO}_{2} / \mathrm{OMC}$ (grey line). All weights are normalized by the initial amount of carbonaceous carrier, $m_{\mathrm{C}}$. PtAA/AC and Pt/AC are not shown here.

Hydrolysis yields were lower than 1 for all samples, which indicated that a part of each precursor desorbed from the carrier before reacting. The yields were supposedly dependent on each precursor's reactivity, its adsorption isotherm on the carrier and its gas phase diffusivity. Also the carrier pore structure and/or the alkoxide concentration on the carrier are likely to influence the hydrolysis yield. A detailed analysis of the factors influencing the hydrolysis yield was not focus of this study.

Table 2. Metal (oxide) loadings of hydrolysis products

\begin{tabular}{|c|c|c|c|c|c|c|}
\hline & $\begin{array}{c}\mathrm{TiO}_{2} / \mathrm{OMC} \\
\text { (from } \\
\text { TTIP) }\end{array}$ & $\begin{array}{c}\mathrm{TiO}_{2} / \mathrm{AC} \\
\text { (from } \\
\text { TTIP) }\end{array}$ & $\begin{array}{c}\mathrm{TiO}_{2} / \mathrm{AC} \\
\text { (from } \\
\text { TTM) }\end{array}$ & $\mathrm{V}_{2} \mathrm{O}_{5} / \mathrm{AC}$ & $\left.\mathrm{Rh}_{\mathrm{x}} \mathrm{O}_{\mathrm{y}} / \mathrm{AC} *\right)$ & $\mathrm{PtO} / \mathrm{AC}$ \\
\hline $\begin{array}{l}\text { molar loading / } \\
\text { mol (g-carrier) }\end{array}$ & $3.8 \times 10^{-4}$ & $1.5 \times 10^{-3}$ & $3.4 \times 10^{-4}$ & $1.0 \times 10^{-3}$ & $3.3 \times 10^{-4}$ & $9.5 \times 10^{-5}$ \\
\hline $\begin{array}{l}\text { weight loading / } \\
\text { g (g-carrier) }\end{array}$ & 0.030 & 0.122 & 0.027 & 0.191 & 0.082 & 0.018 \\
\hline $\begin{array}{l}\text { Hydrolysis yield / } \\
\text { mol mol }^{-1}\end{array}$ & 0.41 & 0.67 & 0.58 & 0.92 & 0.95 & 0.75 \\
\hline
\end{tabular}


Characterization of hydrolysis products. The identification of metal (oxide) formed in the pores of the carbon carrier by using SEM/EDS, XPS and XRD turned out to be difficult. An EDS spectrum and the corresponding titanium map of $\mathrm{TiO}_{2} / \mathrm{OMC}$ are shown in Figure 5. The elemental map showed that titanium was well-dispersed in the carrier material. Titanium peaks in the spectrum were of relatively low intensity, compared to the silicon peak. The silicon peak resulted from silica residues of the SBA template that was used for the synthesis of OMC. However, the amount of silica remaining in the OMC was negligible, as can be seen from the weight loss curve of combustion of pure OMC. The amount of titania, as estimated from the TG analysis, was significantly higher than the silica amount.

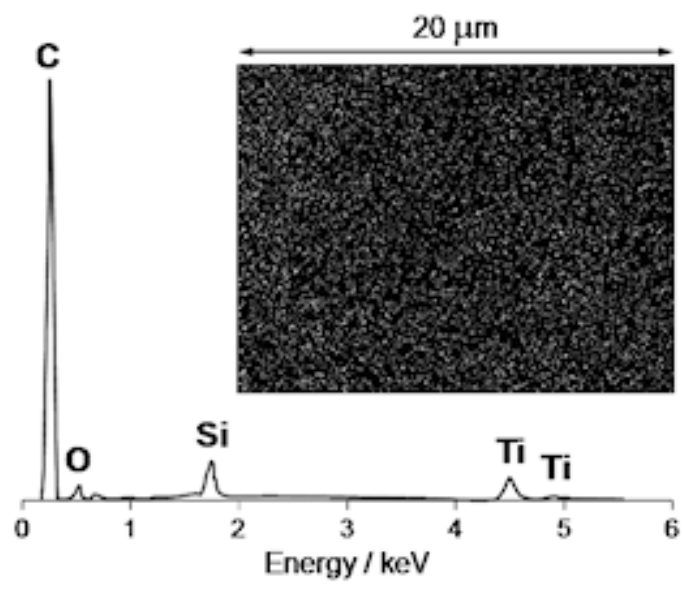

Figure 5. EDS spectrum and corresponding $\mathrm{Ti}$ map of $\mathrm{TiO}_{2} / \mathrm{OMC}$, recorded at 5,000 $\times$ magnification

The same phenomenon was observed for XPS measurements, as is exemplary shown in Figure 6, depicting part of the XPS spectrum of $\mathrm{V}_{2} \mathrm{O}_{5} / \mathrm{AC}$. Although $0.19 \mathrm{~g}$ (g-carrier) ${ }^{-1}$ of vanadia are contained in the sample, the $\mathrm{V}_{2} \mathrm{O}_{5}$ peak is of considerably low intensity (117 cps). Even the Si 2p peak, resulting from the ash content of AC, showed higher intensity (151 cps), although ash makes up for only approximately $0.04 \mathrm{~g}$ (g-carrier) ${ }^{-1}$ in the pure AC. In the samples other than $\mathrm{V}_{2} \mathrm{O}_{5} / \mathrm{AC}$ and $\mathrm{TiO}_{2} / \mathrm{AC}$, no metal (oxide)s were traceable at all by XPS analyses. With XPS it is to be considered that this technique produces and analyzes electrons of low energies. Since such electrons are absorbed easily by surrounding solid matter, XPS can be applied successfully only to surface analyses, allowing for an 
analysis deepness of only ca. 2 to 5 nm. ${ }^{10}$ Therefore low peak intensities in EDS and XPS measurements were supposed to indicate that by far the largest amount of metal (oxide)s was contained inside the carbon matrices.

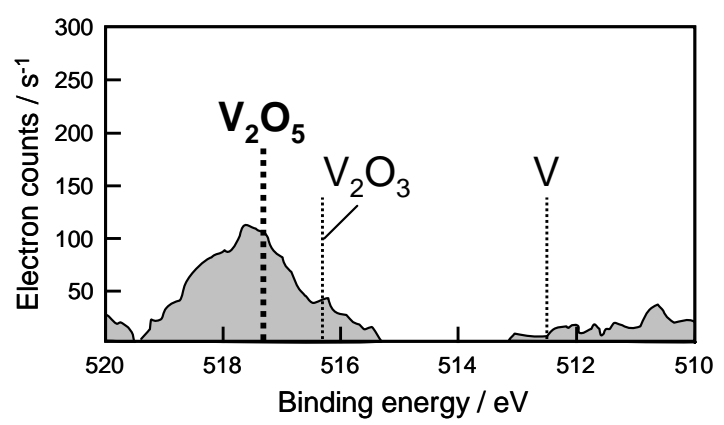

Figure 6. $\mathrm{V} 2 \mathrm{p}_{3 / 2}$ peaks in the XPS spectrum of $\mathrm{V}_{2} \mathrm{O}_{5} / \mathrm{AC}$

When X-ray diffraction patterns of product samples were observed, most samples did not reveal any peaks, as can be seen in the example patterns shown in Figure 7. This may indicate that even in case of samples containing reduced metal, X-ray amorphous phases were obtained from the hydrolysis reaction. Creation of amorphous metals is not an uncommon phenomenon, and has been described e.g. in preparation of metal films from organometallic precursors ${ }^{11}$ or supported rhodium catalysts. ${ }^{12}$ Apart from poor crystallinity, however, the absence of peaks may also be explained by small crystallite sizes: Line broadening, resulting from small crystallite sizes, alongside with low peak intensities due to small volumes of the crystals lead to reduction of the signal-to-noise ratio, and peaks of nanosized crystals were obliterated by the carbon signals. 

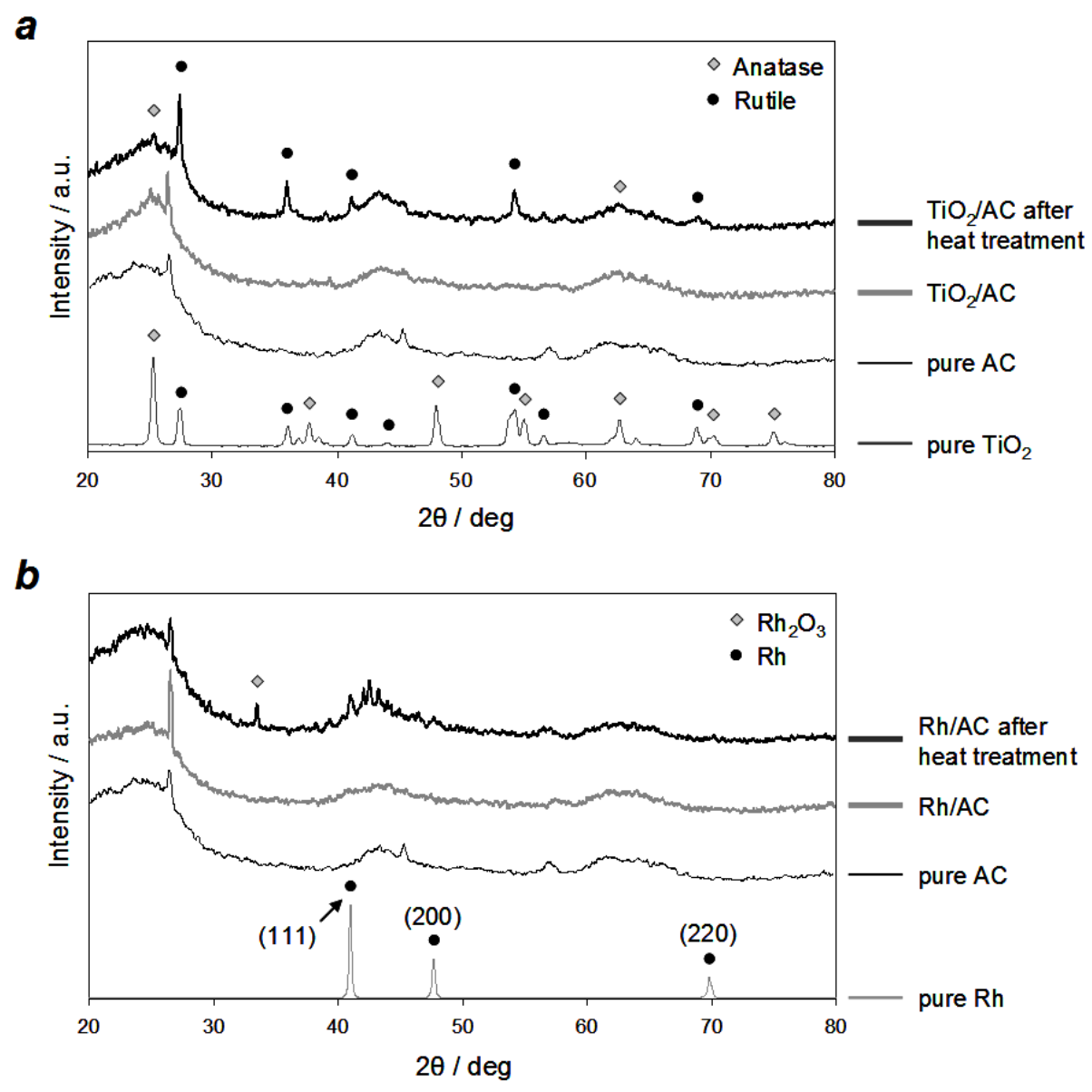

Figure 7. XRD spectra of (a) $\mathrm{TiO}_{2} / \mathrm{AC}$ prepared from hydrolysis of TTIP/AC, and (b) $\mathrm{Rh}_{\mathrm{x}} \mathrm{O}_{\mathrm{y}} / \mathrm{AC}$ each before and after a heat treatment of $2 \mathrm{~h}$ at $800{ }^{\circ} \mathrm{C}$ under $\mathrm{N}_{2}$ gas flow. The pattern of each sample is compared to the XRD patterns of the pure AC and the respective pure metal (oxide).

Effect of precursor reactivity on the product conformation. Although the analyses described before were not successful to explicitly prove the metal (oxide) formation, TEM observations clearly showed that metal (oxide) had formed within the pores of the carrier material, as can be seen from the micrographs presented in Figure 8. In case of TTM, PtAA and RhDCAA precursors, large amounts of well-dispersed, small nanoparticles with a narrow size-distribution were observed.

However, the TEM observations also revealed that the conformations of obtained metal (oxide) largely varied with precursor. No nanoparticles were found in the samples prepared from TTIP and VOTIP precursors. Due to the different findings as concerns the conformation of obtained metal (oxide), that is, particulate products on the one hand and non-particulate on the other, it was hypothesized that 
the tendency to form particulate products was related to the rate of formation of each respective metal (oxide) product. In order to judge this dependence, the reactivity of each precursor towards hydrolysis was estimated qualitatively by observation upon contacting with $\mathrm{H}_{2} \mathrm{O}$. Whereas RhDCAA did not reveal any signs of reaction (e.g. gas formation, color change, temperature change etc.) when mixed with liquid water, VOTIP showed quick evolution of orange streaks in the bulk liquid (indicating the formation of $\mathrm{V}_{2} \mathrm{O}_{5}$ ) merely when contacted with the moisture contained in ambient air.

The effect of altering the reactivity by variation of the precursor on the product conformation is depicted on the left side of Figure 8, which shows a sequence of representative TEM images of the hydrolysis products of each alkoxide precursor with respect to its reactivity. The micrographs show that the nanoparticles which were formed by the hydrolysis of TTM were of surprisingly high number concentration. The particles were almost monodisperse and had an average diameter of ca. 5 nm. Also with PtAA and RhDCAA precursors, large amounts of such nanoparticles were obtained, however, the particle number concentration appeared to decrease in the order of precursors TTM $>$ PtAA $>$ RhDCAA, which complies with the order of reactivity. 


\section{after heat treatment}

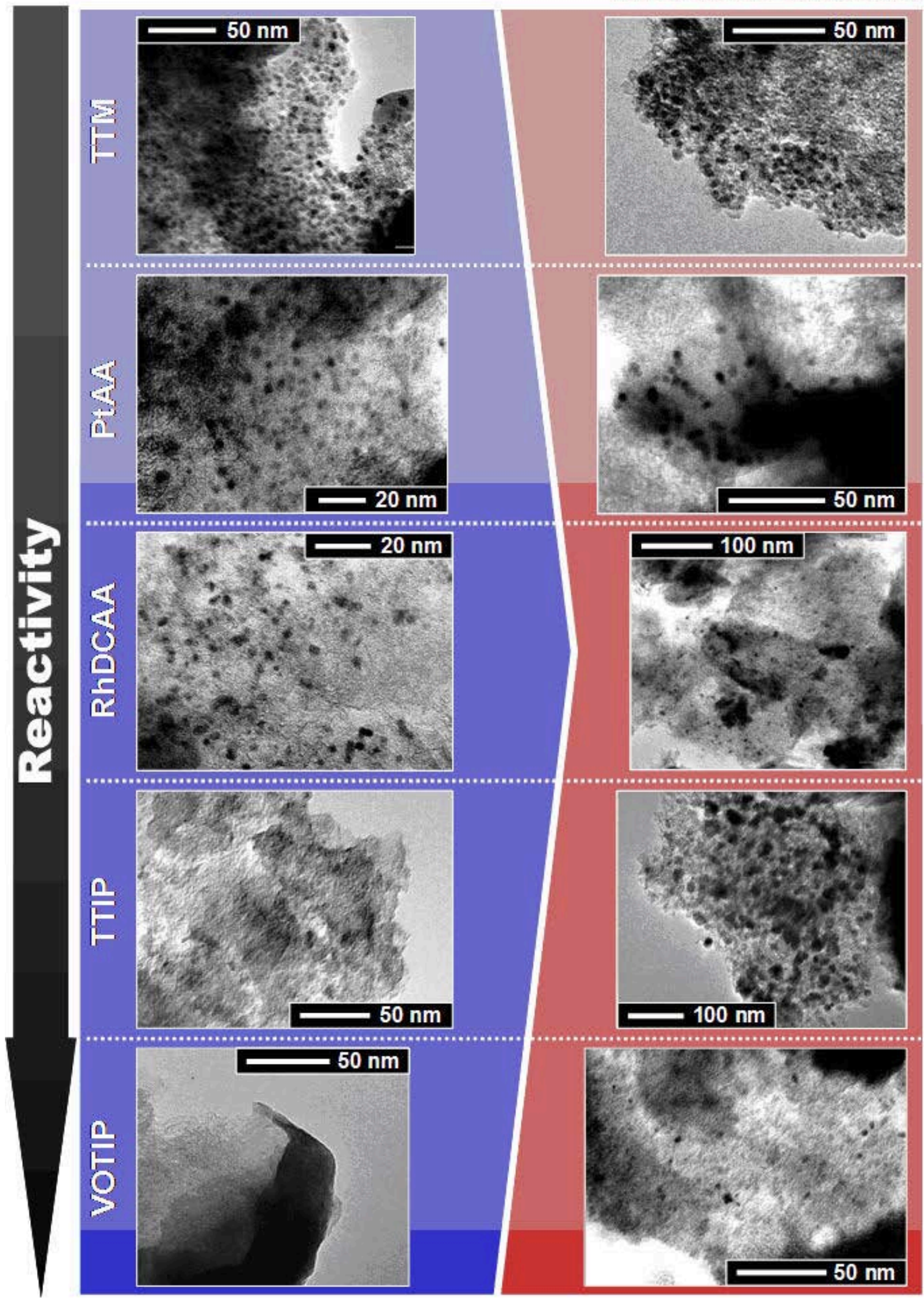

Figure 8. Exemplary TEM bright field images of hydrolysis products of various alkoxide precursors on AC carrier - the influence of the precursor's reactivity and the effect of a subsequent heat treatment on the formation of nanoparticles. 
On the other hand, in the $\mathrm{TiO}_{2} / \mathrm{AC}$ samples prepared from TTIP/AC and in the $\mathrm{V}_{2} \mathrm{O}_{5} / \mathrm{AC}$ samples no nanoparticles could be observed at all, although the metal oxide loading was very high in both samples. In the $\mathrm{TiO}_{2} / \mathrm{AC}$ sample no product was directly observable. At very high magnifications, however, a few areas in the sample revealed crystal structures, as shown in Figure 9. The crystal lattice planes shown in the figure had a spacing of approximately $0.35 \mathrm{~nm}$, which corresponds to the three major crystalline structures of $\mathrm{TiO}_{2}$ (anatase, rutile and brookite, which have comparable lattice spacings). Furthermore, the observed crystal planes were different from graphitic carbon that can be found in pure AC: Graphite layers in AC usually do not appear in stacks of more than approximately 5 crystal planes and are usually convoluted, having bending radii of only a few nanometers. The micrograph in Figure 9, though, shows a stack of more than 20 crystal planes which are not bent over a length of ca. $6 \mathrm{~nm}$. It remained unclear, though, whether observed titania was crystallized completely. In all likelihood, the product formed under the applied conditions was mostly of amorphous state, since the hydrolysis conditions were very mild. As the observed crystallized titania was furthermore of small crystallite sizes, this possibly explains the absence of peaks in the XRD pattern.

All bright field images of this $\mathrm{TiO}_{2} / \mathrm{AC}$ sample were of low contrast, which made it hard to locate and observe the titania contained in the sample. Therefore the structure of the titania obtained from the TTIP hydrolysis remained unclear. Possibly, most of the titania seeds may have been too small to be observed in the carbon matrix. Another possibility is that titania may have been obtained in the form of thin sheets covering the pore walls of the carrier. 


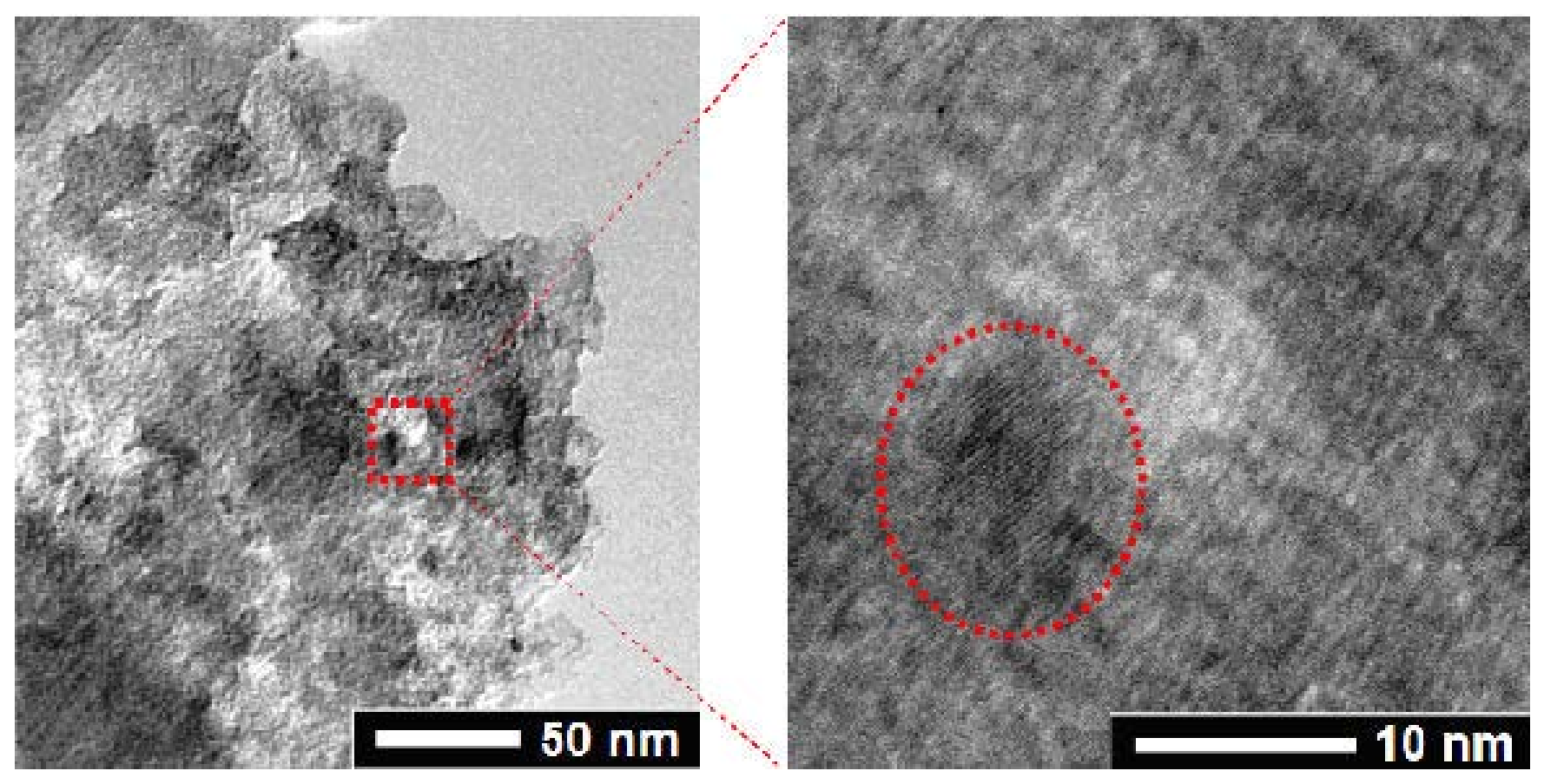

Figure 9. TEM bright field images of $\mathrm{TiO}_{2} / \mathrm{AC}$ prepared from hydrolysis of TTIP/AC.

Hydrolysis of VOTIP/AC yielded vanadia structures of poor crystallinity, which were partly very large and were of indefinite forms, as is shown in Figure 10. At high magnification, the highly irregular and not perfectly straight crystal planes showed non-uniform interplanar spacing and a high concentration of defects. These vanadia structures appeared relatively transparent in the TEM pictures, indicating flattened shapes.

The high hydrolysis yield of the VOTIP/AC sample indicated that only a relatively small portion of the VOTIP evaporated before reacting. In addition, the carbon material of the carrier and the $\mathrm{V}_{2} \mathrm{O}_{5}$ appeared to be interconnected in the bright field TEM pictures. It is thus supposed that the vanadia structures may have formed on the pore walls or were a kind of casting of the slit-like mesopores of the AC carrier. 

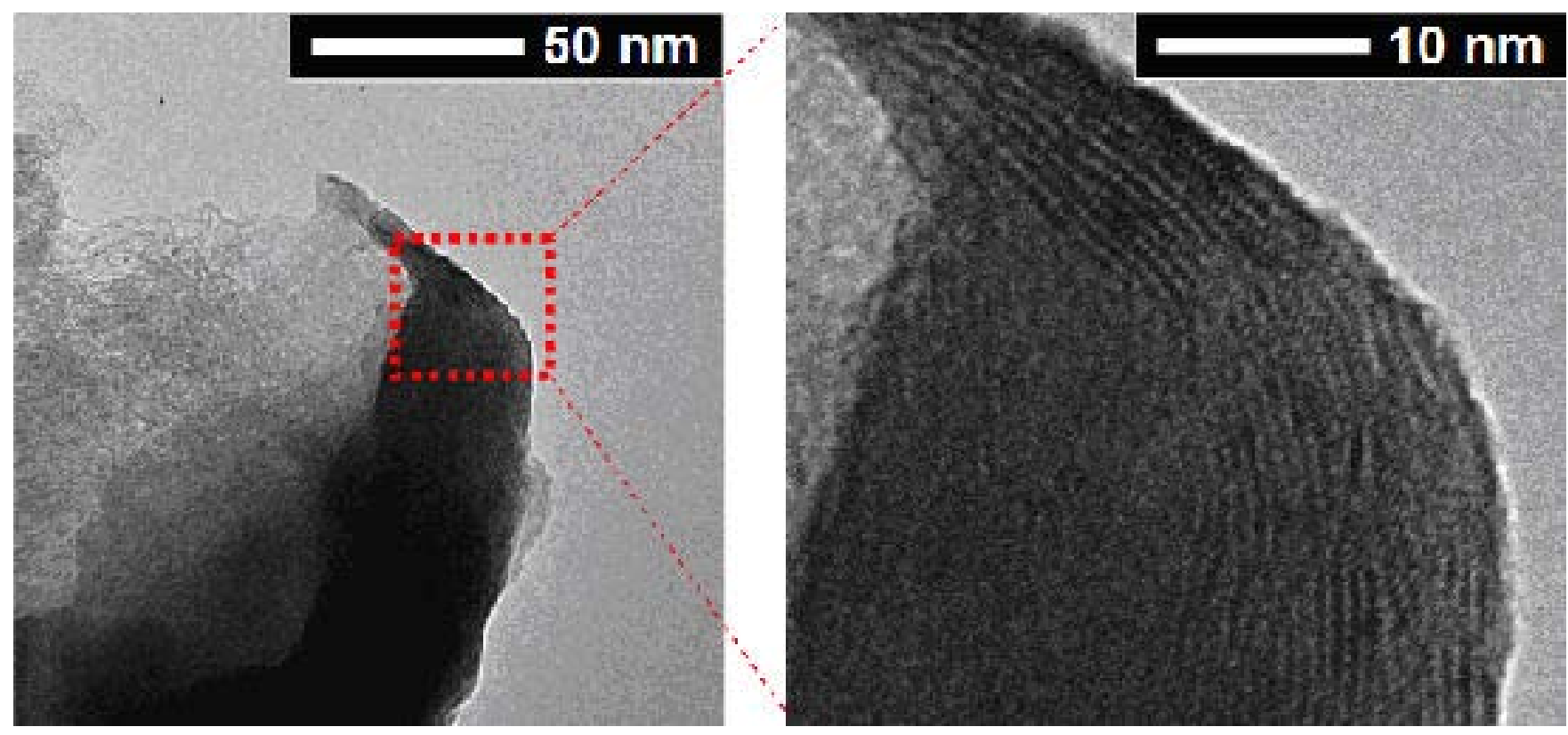

Figure 10. TEM bright field images of $\mathrm{V}_{2} \mathrm{O}_{5} / \mathrm{AC}$ prepared from hydrolysis of VOTIP/AC.

Effect of heat treatment and particle formation mechanisms. The right column of Figure 8 shows a sequence of TEM images of the same samples after calcination. By subsequent heat treatment of the $\mathrm{TiO}_{2} / \mathrm{AC}$ sample prepared from TTM/AC, the Pt/AC and the $\mathrm{Rh}_{\mathrm{x}} \mathrm{O}_{\mathrm{y}} / \mathrm{AC}$ samples, particle sizes partly increased up to ca. $25 \mathrm{~nm}$, and some agglomerations appeared. On the other hand, generally, the particulate structure of the product was not altered.

For $\mathrm{TiO}_{2} / \mathrm{AC}$, which was prepared from TTIP/AC, and the $\mathrm{V}_{2} \mathrm{O}_{5} / \mathrm{AC}$ sample, however, nanoparticles appeared after the calcination, most notably for the $\mathrm{TiO}_{2} / \mathrm{AC}$ sample, where high concentrations of titania nanoparticles were observed throughout the carrier material. This observation suggested that the metal oxides in these cases underwent some restructuring process and thus nanosized particles were formed from the non-particulate product obtained from the hydrolysis reaction.

The structure change also affected the XRD patterns, as shown in Figure 7. In case of $\mathrm{TiO}_{2} / \mathrm{AC}$, clear rutile and also anatase peaks appeared in the spectrum after the calcination. The crystal size calculated from peak broadness by the Scherrer equation agreed with the TEM observations, which showed relatively large particles (up to ca. $25 \mathrm{~nm}$ ). It is thus supposed that the calcination activated 
crystallization and crystal growth of titania and that the geometric shape of the product changed alongside.

Also in case of $\mathrm{Rh}_{\mathrm{x}} \mathrm{O}_{\mathrm{y}} / \mathrm{AC}$, peaks in the XRD pattern for both reduced rhodium metal, $\mathrm{Rh}(0)$ and the oxidized state, Rh(III) were found after the calcination. TEM revealed that the size of several nanoparticles increased from 3 to $10 \mathrm{~nm}$ in the hydrolysis products to up to ca. $25 \mathrm{~nm}$ in the calcined products, which was in good agreement with the crystallite size calculated from the XRD peaks.

The restructuring effect is more clearly shown by changes in the pore size distribution. $\mathrm{TiO}_{2} / \mathrm{OMC}$ allowed for facile investigation of the effects of product formation and restructuring, since the OMC carrier offered a relatively uniform pore structure, which was preserved even after the calcination. Furthermore, the $\mathrm{TiO}_{2}$ loading was relatively high and the restructuring occured in the titania formed from the TTIP precursor. Figure 11 compares the pore size distributions of pure OMC with that of $\mathrm{TiO}_{2} / \mathrm{OMC}$, the latter before and after the heat treatment. Titania formation by hydrolysis of TTIP/OMC significantly reduced the pore volume around the maximum in the pore size distribution of the OMC carrier (see curve $b$ in Figure 11). The reduction in pore volume was approximately 7 times higher than the volume of $\mathrm{TiO}_{2}$ formed, indicating that the pores were partly blocked by the titania. After calcination, however, the incremental pore volume was found to increase again (see curve $c$ in Figure 11). Here, the ratio of the reduction in pore volume (compared to the pure OMC) to the volume of $\mathrm{TiO}_{2}$ dropped to ca. 1.3. As shown by TEM, titania restructured into particulates, which largely removed blockage of the pores and consequently the reduction in pore volume accorded to the volume occupied by $\mathrm{TiO}_{2}$ particles. This result cannot be fully explained at this stage. If, in case of the hydrolysis products (before calcination), titania seeds were very small (as suggested by the absence of any observable $\mathrm{TiO}_{2}$ in the TEM micrographs) and grew to a visible size by the calcination, it is not plausible how the very small titania seeds can cause pore blockage and why this blockage can be removed by the calcination. It may be possible, however, that titania obtained from the hydrolysis formed a sheet-like product on the pore walls in the first stage. If such a sheet-like titania did not cover the pore walls uniformly, bent and protruding titania sheets may render part of the pores inaccessible. This hypothesis cannot be directly 
proved at the current experimental stage. The restructuring of nanosized films to form particles under the influence of heat would however be consistent with results described in the literature on amorphous noble metal nanofilms agglomerating to nanoparticles during crystallization by heating in air. ${ }^{13}$ Similar observations were made when the crystallization behavior of titania nanosheets was studied: Upon heat treatment, multilayered nanosheets of amorphous titania restructured into nanosized anatase particulates. $^{14,15}$

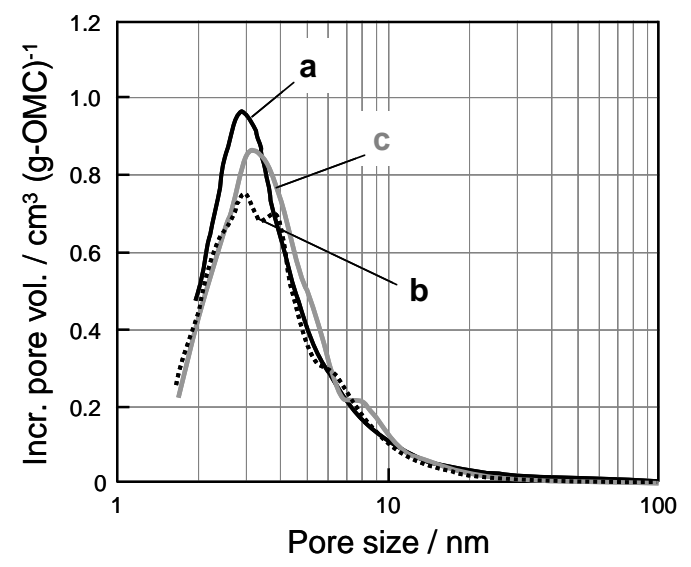

Figure 11. Pore size distributions of (a) pure OMC carrier, (b) $\mathrm{TiO}_{2} / \mathrm{OMC}$ and (c) $\mathrm{TiO}_{2} / \mathrm{OMC}$ after heat treatment $\left(2 \mathrm{~h}\right.$ at $800{ }^{\circ} \mathrm{C}$ under $\mathrm{N}_{2}$ flow)

Table 3. Formation of nanoparticles in relation to precursor reactivity and subsequent annealing for $2 \mathrm{~h}$ at $800{ }^{\circ} \mathrm{C}$ under $\mathrm{N}_{2}$ flow: “- ” = no particles observed; “+” = sparse amount of particles observed in a few regions of the carrier material, “+++” high amount of particles observed throughout the carrier material

\begin{tabular}{cccccc}
\hline precursor: & TTM & PtAA & RhDCAA & TTIP & VOTIP \\
\hline $\begin{array}{c}\text { observed reactivity } \\
\text { in bulk phase: }\end{array}$ & very low & very low & low & high & very high \\
particle formation: & ++ & + & + & - & - \\
$\begin{array}{c}\text { particles after heat } \\
\text { treatment (HT): }\end{array}$ & ++ & + & $+(+)$ & +++ & + \\
\hline
\end{tabular}


In this study, product formation by the chemical reaction and exposure to heat were decoupled by applying hydrolysis reaction at mild conditions and conducting a heat treatment subsequently. With this approach the effects of altering precursor reactivities and the role of heat in the formation of spheroidal nanoparticles were clarified separately. The effects of both precursor reactivity and heat treatment on the evolution of particulates, are summarized in Table 3. The thermodynamically stable form of metal oxides, spheroidal particles, can be formed either directly or by subsequent restructuring. Direct particle formation was observed for low precursor reactivities, i.e. for TTM, PtAA and RhDCAA precursors. On the other hand, the highly reactive precursors TTIP and VOTIP yielded non-particulate product, since in this case the product was formed so rapidly that the period of time which was needed for the product formation was not sufficient to reach the thermodynamically stable state. Thus a metastable state persisted despite of its supposedly high specific surface energy. However, subsequent exposure of the metastable product to heat provided the activation energy to initiate crystallization and crystal growth processes. These were accompanied by modification of the geometrical alignment, which helped to minimize the specific surface area of the product and thus reach a thermodynamically stabler form, i.e. spheroidal particles.

In this context, the temperature applied to the calcination may be an important parameter to control the crystal growth and thus the final nanoparticle size.

\section{Conclusions}

A nanoreactor was applied for preparation of a variety of nanoscale metal (oxide) by hydrolysis at very mild conditions. Whereas in our previous work the pyrolysis reaction of titanium alkoxide precursors had been studied for the preparation of nanosized titania, the present work also successfully implemented the nanoreactor concept for hydrolysis reactions of various metal alkoxides adsorbed on a carrier material. Thus nanosized vanadia and titania as well as rhodium (oxide) and platinum structures were prepared inside the pores of carbonaceous carrier materials. 
In case of low precursor reactivities, direct particle formation by the hydrolysis reaction was observed and large amounts of well-dispersed titania, platinum and rhodium nanoparticles with a uniform sizedistribution around ca. $5 \mathrm{~nm}$ were obtained. On the other hand, high precursor reactivities yielded nonparticulate product. The non-particulate product was a metastable state of the product and may be of a sheet-like or flattened shape. Calcination of the hydrolysis products initiated crystallization and crystal growth processes that caused the products to restructure into nanoparticles.

With the knowledge gained in this study, the nanoreactor hydrolysis concept is expected to be applied for successful preparation of several sorts of supported nanosized metals and metal oxides.

\section{References}

(1) Yang, P. (ed.) The Chemistry of Nanostructured Materials; World Scientific: Singapore, 2003

(2) Fendler, J. H. (ed.) Nanoparticles and Nanostructured Films; Wiley-VCH: Weinheim/Germany, 1998

(3) Aiken III, J. D.; Finke, R. G. A review of modern transition-metal nanoclusters: their synthesis, characterization, and applications in catalysis. J. Mol. Catal. A: Chem. 1999, 145, 1-44

(4) Taguchi, A.; Schüth, F. Ordered mesoporous materials in catalysis. Micropor. Mesopor. Mater, 2005, $77,1-45$

(5) Miura, K.; Kawase, M.; Ashida, R.; Gerlach, I.; Yamamoto, T. Nano-reactor for producing high performance nanomaterials. Chem. Eng. Sci. 2007, 62, 5655-5660

(6) Kim, T. W.; Ryoo, R.; Gierszal, K. P.; Jaroniec, M.; Solovyov, L. A.; Sakamoto, Y.; Terasaki, O. Characterization of mesoporous carbons synthesized with SBA-16 silica template. J. Mater. Chem. 2005, 15, 1560-1571

(7) Kim, T. W.; Ryoo, R.; Kruk, M.; Gierszal, K. P.; Jaroniec, M.; Kamiya, S.; Terasaki, O. Tailoring the Pore Structure of SBA-16 Silica Molecular Sieve through the Use of Copolymer 
Blends and Control of Synthesis Temperature and Time. J. Phys. Chem. B 2004, 108, 1148011489

(8) Dollimore, D.; Heal, G. R. An improved method for the calculation of pore size distribution from adsorption data. J. Appl. Chem. 1964, 14, 109-114

(9) Dollimore, D.; Heal, G. R. Pore-size distribution in typical adsorbent systems. J. Colloid Interface Sci. 1970, 33 (4), 508-519

(10) West, A. R. Basic Solid State Chemistry; John Wiley \& Sons: New York, 1999 (2nd ed.)

(11) Kirss, R. U. Organometallic chemical vapor deposition using allyl precursors. Appl. Organometal. Chem., 1992, 6, 609-617

(12) Wanke, S. E.; Doughart, N. A. Interaction of Hydrogen, Oxygen, and Carbon-Monoxide with Supported Rhodium. J. Catal., 1972, 24 (3), 367

(13) Mizsei, J.; Pirtthiaho, L.; Karppinen, M.; Lantto, V. Nanocatalyst sensitizers by agglomeration of nanofilms. Sens. Act. B 2000, 65, 195-198

(14) Fukuda, K.; Sasaki, T.; Watanbe, M.; Nakai, I.; Inaba, K.; Omote, K. Novel Crystal Growth from a Two-Dimensionally bound Nanoscopic System. Formation of Oriented Anatase Nanocrystals from Titania Nanosheets. Cryst. Growth Des. 2003, 3, 281-283

(15) Fukuda, K.; Ebina, Y.; Shibata, T.; Aizawa, T.; Nakai, I.; Sasaki, T. Unusual Crystallization Behaviors of Anatase Nanocrystallites from a Molecularly Thin Titania Nanosheet and Its Stacked Forms: Increase in Nucleation Temperature and Oriented Growth. J. Am. Chem. Soc. 2007, 129, 202-209 